Área Abierta. Revista de comunicación

audiovisual y publicitaria

ISSN: 2530-7592 / ISSNe: 1578-8293

https://dx.doi.org/10.5209/arab.80081

\title{
Estrategias de comunicación, educativas y vitales: ¿resistencia numantina?
}

\author{
María José Revuelta Bayod ${ }^{1}$ \\ Recibido: 25 de enero de 2022 / Aceptado: 16 de febrero de 2022
}

Resumen. La profesión académica, docente e investigadora, está repleta de interacciones con profesionales que adoptas como ejemplo en circunstancias que casi pasan desapercibidas en el momento. Pasado el tiempo, haciendo una retrospectiva, visualizas los acontecimientos que te marcaron como una interacción recíproca entre el sustento racional que requiere esta profesión y las inevitables, y a veces enigmáticas, emociones. Porque el camino de la ciencia nunca estuvo exento de ellas.

Palabras clave: manipulación de medios; medios de comunicación públicos; concentración de medios

\section{[en] Communicational, Educational and Vital Strategies: Numantine Resistance?}

\begin{abstract}
The academic teaching and research profession is full of interactions with professionals that you adopt as an example in circumstances that almost go unnoticed at the time. Over time, doing a retrospective, you visualize the events that marked you as a reciprocal interaction between the rational sustenance that this profession requires and the inevitable, and sometimes enigmatic, emotions. Because the path of science was never exempt from them.
\end{abstract}

Keywords: media manipulation; television; public media; media concentration

Cómo citar: Revuelta Bayod, M. J. (2022). Estrategias de comunicación, educativas y vitales: ¿resistencia numantina? Área Abierta. Revista de comunicación audiovisual y publicitaria 22 (1), 99-101, https://dx.doi.org/10.5209/arab.80081

Resistencia numantina es una expresión que escuché utilizar a Enrique Bustamante varias veces. Solía usarla para calificar y enfatizar las posiciones que permanecían inquebrantables ante perspectivas que él consideraba democráticas y que eran loables de ser defendidas:

Yo creo que, tanto en Canal Nou como en la Comunidad de Madrid, ha habido movimientos muy importantes de defensa de los profesionales, de denuncia de la manipulación, de resistencia también y de solidaridad de la sociedad civil, pero sabemos que esos procesos son complejos cuando hay gobiernos con mayoría absoluta $[. .$.$] , que resisten numantinamente todas las defensas que se puedan$ hacer del servicio público. [...]

A partir del 2009 comienza un proceso de contrarreforma desde el punto de vista democrático de la propia ley del 2006, del propio modelo de RTVE: empie-

1 Universidad Internacional Villanueva (España).

E-mail: mrevuelta@villanueva.edu

ORCID: https://orcid.org/0000-0002-4255-6619 
zan a introducirse elementos negativos en ese cambio de reforma transparente que se había iniciado. (OMI, 2011)

Esta cita es parte de la entrevista que le realizamos desde el grupo de investigación de la UCM Observatorio de Medios Informativos para el documental Pongamos que hablo de Telemadrid y del que, con generosidad, formó parte en sus inicios. Fue llevada a cabo seis años después de que Enrique Bustamante formase parte del Comité para la Reforma de los Medios de Titularidad Pública. Como siempre que le solicité ayuda, su respuesta fue rápida y afirmativa: en el momento de la entrevista hizo fluido y más que interesante el proceso, además de recomendarme el contacto de Agustín García Matilla, con lo que el guion quedó enriquecido con una nueva perspectiva que ahora percibo imprescindible.

Mi experiencia con Enrique comenzó en el curso de doctorado que impartió sobre Industrias Culturales. Con dos compañeras más nos enseñó con teoría, pero más con trabajos prácticos que exponíamos en clase, a profundizar sobre cómo hacer una tesis, cómo estructurarla y la importancia de las metodologías cualitativas que siempre defendió. Una vez en clase mencioné la publicación Le Monde diplomatique y expresé de manera ingenua mi descubrimiento ante un medio que ofrecía perspectivas muy diferentes. Después de disertar sobre el Informe MacBride, que tanto mentaba la concentración exponencial de medios que estaba sucediendo en el año 2000 y el pensamiento único, me comentó en un descanso de clase: "No solo lo conozco, sino que formo parte del Consejo de Redacción". Mi curiosidad y mi atención, que no estaban disminuidas en sus clases, se incrementaron.

Además de que lo escuché en sus propias palabras, tenía fama de no dirigir cualquier tesis por su nivel de exigencia y profesionalidad. Por esta razón y por más, supuso un gran orgullo que aceptase ser el presidente de mi tribunal. Mi director de tesis me recomendó incluir una cita suya, como muestra de respeto, pero reconozco mi ineptitud en estas cuestiones diplomático-burocráticas y a él no pareció importarle en absoluto. Recuerdo, con un gran afecto, el comentario principal a mi trabajo: "Tu mejor virtud es tu peor defecto, y tu peor defecto es tu mejor virtud". Pero quizá por ese comportamiento paradójico es por lo que siempre aceptó mis propuestas. Me hacen sospechar sus continuos consejos sobre mi necesidad de ser más pragmática. Lo desconozco. Me quedo con la duda.

Me gustaría haber tenido una última entrevista-encuentro con él y preguntarle sobre su visión de estos tiempos entrópicos que vivimos. Sobre el nivel de concentración que se ha alcanzado en los medios, sobre la evolución del pensamiento único y si, enmarcado en la ley de los contrarios, percibía y cómo una transmutación de dominado a dominante; además de las nuevas realidades que se están generando en este nuevo o evolucionado marco epistemológico. Y relacionado con éste, sobre el grado de sofisticación o reducción "según el criterio que se adopte" en la manipulación del lenguaje, las estructuras cognitivas derivadas y sus consecuencias en todos los ámbitos sociales.

Sí que le asocio con ese sustantivo, resistencia; no sé si numantina. No sé si en algún momento de su trayectoria vital llegó a verse en una situación tan extrema que pudiera calificarse como tal, pero a mí siempre me demostró ser un académico íntegro y fiel a sus principios. Alguien en quien confiar y en las palabras que decía. $\mathrm{Y}$ para eso hay que tener resistencia. Agradezco a Enrique los conocimientos que 
me aportó, los apoyos que le solicité y que nunca me negó, y el haber compartido conmigo pequeños fragmentos de la vida académica.

\section{Bibliografía}

Observatorio de Medios Informativos (2011). Pongamos que hablo de Telemadrid. [Documental]. Biblioteca de Ciencias de la Información (UCM). Videoteca Antonio Lara. DVD791.43-92PON. Recuperado de https://www.youtube.com/watch?v=dBSwQJFL6r4 (Fecha de acceso: 18/01/2022). 